\title{
A Novel Phosphodiesterase 1 Inhibitor DSR-141562 Exhibits Efficacies in Animal Models for Positive, Negative, and Cognitive Symptoms Associated with Schizophrenia ${ }^{\mathbb{S}}$
}

\author{
Takeshi Enomoto, Ayaka Tatara, Masao Goda, Yohei Nishizato, Kantaro Nishigori, \\ Atsushi Kitamura, Mami Kamada, Shiori Taga, Takashi Hashimoto, Kazuhito Ikeda, \\ and Yuki Fujii \\ Drug Research Division, Sumitomo Dainippon Pharma, Co., Ltd., Osaka, Japan
}

Received June 17, 2019; accepted September 18, 2019

\begin{abstract}
In our drug discovery program, we identified a novel orally available and brain-penetrant phosphodiesterase (PDE) 1 inhibitor, 3-methyl-7-(tetrahydro-2H-pyran-4-yl)-2-\{[trans-4(trifluoromethyl)cyclohexyl]-methoxy\}imidazo[5,1-f][1,2,4]triazin$4(3 H)$-one (DSR-141562). In the present study, we characterized the preclinical profile of DSR-141562. This compound has preferential selectivity for predominantly brain-expressed PDE1B over other PDE1 family members, and high selectivity for the PDE 1 family over other PDE families and 65 other tested biologic targets. Oral administration of DSR-141562 at $10 \mathrm{mg} / \mathrm{kg}$ slightly elevated the cGMP concentration, and it potently enhanced the increase of cGMP induced by a dopamine $D_{1}$ receptor agonist in mouse brains. The cGMP level in monkey cerebrospinal fluid was also elevated after treatment with DSR-141562 at 30 and $100 \mathrm{mg} / \mathrm{kg}$ and could be used as a translational biomarker. Since PDE1B is believed to regulate dopaminergic and glutamatergic signal transduction, we evaluated the effects of this compound using schizophreniarelated behavioral assays. DSR-141562 at $3-30 \mathrm{mg} / \mathrm{kg}$ potently
\end{abstract}

inhibited methamphetamine-induced locomotor hyperactivity in rats, while it had only minimal effects on the spontaneous locomotor activity. Furthermore, DSR-141562 at 1-100 mg/kg did not induce any signs of catalepsy in rats. DSR-141562 at $0.3-3 \mathrm{mg} / \mathrm{kg}$ reversed social interaction and novel object recognition deficits induced by repeated treatment with an $\mathrm{N}$-methyl-D-aspartate receptor antagonist, phencyclidine, in mice and rats, respectively. In common marmosets, DSR141562 at 3 and $30 \mathrm{mg} / \mathrm{kg}$ improved the performance in object retrieval with detour tasks. These results suggest that DSR-141562 is a therapeutic candidate for positive, negative, and cognitive symptoms in schizophrenia.

\section{SIGNIFICANCE STATEMENT}

This is the first paper showing that a phosphodiesterase 1 inhibitor is efficacious in animal models for positive and negative symptoms associated with schizophrenia. Furthermore, we demonstrated that this compound improved cognitive function in the common marmoset, a nonhuman primate.

\section{Introduction}

Schizophrenia is a severe psychiatric disorder that consists of positive (e.g., delusions, hallucinations, and thought disorder), negative (e.g., flattened affect, amotivation, and poverty of speech), and cognitive symptoms (e.g., working memory, cognitive flexibility, and attention deficits) (Crow, 1980; Sharma and Harvey, 2000). Although positive symptoms are currently treated with dopamine $\mathrm{D}_{2}$ receptor antagonists, most antipsychotics work within a narrow therapeutic dose range with regard to extrapyramidal side effects (Casey, 1996). Furthermore, the efficacies of current antipsychotics on negative and cognitive symptoms are limited (Woodward

https://doi.org/10.1124/jpet.119.260869.

S This article has supplemental material available at jpet.aspetjournals.org. et al., 2005; Krause et al., 2018). Thus, there is considerable interest in discovering drug candidates with novel mechanisms for treating positive symptoms without having extrapyramidal side effects or for better treating negative and cognitive symptoms.

Cyclic nucleotide phosphodiesterases (PDEs) are enzymes that regulate intracellular signaling by catalyzing the hydrolysis of the second messenger $3^{\prime}, 5^{\prime}$-cAMP and/or $3^{\prime}, 5^{\prime}$-cGMP (Bender and Beavo, 2006; Omori and Kotera, 2007). There are 11 PDE families according to their sequence homologies and enzymatic properties. The PDE1 family, which consists of PDE1A, PDE1B, and PDE1C isoforms, has the unique feature of being activated by binding $\mathrm{Ca}^{2+} /$ calmodulin. Although the PDE1 family is a dual-substrate PDE family, which hydrolyzes both cAMP and cGMP, there are differences in substrate specificities among the three PDE1 isoforms.

ABBREVIATIONS: CSF, cerebrospinal fluid; DSR-141562, 3-methyl-7-(tetrahydro-2H-pyran-4-yl)-2-\{[trans-4-(trifluoromethyl)cyclohexyl]-methoxy\} imidazo[5,1-f][1,2,4]triazin-4(3H)-one; ICR, Institute of Cancer Research; ITI-214, (6aR,9aS)-2-[4-(6-Fluoropyridin-2-yl)benzyl]-5-methyl-3(phenylamino)-5,6a,7,8,9,9a-hexahydrocyclopenta-[4,5]imidazo[1,2-a]pyrazolo[4,3-e]pyrimidin-4-(2H)-one phosphate; m/z, mass-to-charge ratios; PDE, phosphodiesterase; s.c., subcutaneous administration; SKF-82958 hydrobromide, 3-Allyl-6-chloro-1-phenyl-2,3,4,5-tetrahydro-1H-benzo[d] azepine-7,8-diol hydrobromide. 
PDE1A and 1B have a higher affinity for cGMP than cAMP, while PDE1C has a similar affinity for both cAMP and cGMP (Bender and Beavo, 2006; Omori and Kotera, 2007). In addition, three PDE1 isoforms have different tissue distributions. Among the PDE isoforms, PDE1B has the highest expression level in brain, while PDE1A and PDE1C have higher than PDE1B expression levels in peripheral tissues including kidney, thyroid, heart, bladder, and lung (Lakics et al., 2010). The predominance of its distribution in the brain has made PDE1B an attractive drug target for psychologic and neurologic disorders, since peripheral PDE inhibition might cause intolerable adverse effects in humans (Khammy et al., 2017).

The abnormalities of dopamine and glutamate neurotransmission have been hypothesized to be involved in the pathophysiology of schizophrenia (Carlsson et al., 1999). Interestingly, PDE1B is colocalized with dopamine $\mathrm{D}_{1}$ and/or $\mathrm{D}_{2}$ receptors in the striatal and prefrontal cortical neurons in rats and humans (Polli and Kincaid, 1994; Yan et al., 1994; Pekcec et al., 2018). Furthermore, Betolngar et al. (2019) have shown that PDE1 regulates cyclic nucleotide signaling in the context of glutamate and dopamine coincidence. The $\mathrm{Ca}^{2+}$ influx via $N$-methyl-D-aspartate receptors, which are glutamategated $\mathrm{Ca}^{2+}$ channels, transiently activate PDE1B in dopamine $\mathrm{D}_{1}$ or $\mathrm{D}_{2}$ receptor-expressing medium spiny neurons. The theoretical relationship between the function of PDE1B and the pathophysiology of schizophrenia implies the therapeutic potential of PDE1B inhibitors for schizophrenia. Although there are few brain-penetrant compounds with selectivity for PDE1B, a brain-penetrant PDE1 family selective inhibitor-(6aR,9aS)-2-[4-(6-fluoropyridin-2-yl)benzyl]-5methyl-3-(phenylamino)-5,6a,7,8,9,9a-hexahydrocyclopenta[4,5]imidazo[1,2- $a]$ pyrazolo[4,3-e]pyrimidin-4-(2H)-one phosphate (ITI-214) - with approximately 10-fold selectivity for PDE1A and PDE1C over PDE1B has recently been identified ((Li et al., 2016a; Snyder et al., 2016)). It was shown that ITI-214 exhibits efficacy for learning and memory in rodent behavioral models ( $\mathrm{Li}$ et al., 2016a; Snyder et al., 2016). Other research groups have shown that another brain-penetrant PDE1 inhibitor 6-(2-fluoro-4methoxybenzyl)-9-[(tetrahydro-2H-pyran-4-yl)methyl]-8,9,10,11tetrahydropyrido $\left[4^{\prime}, 3^{\prime}: 4,5\right]$ thieno[3,2-e] [1,2,4] triazolo[1,5-c] pyrimidin-5(6H)-one (DNS-0056) improves learning and memory in rodent behavioral models, although its selectivity for PDE1B among PDE1 family members has not been reported (Dyck et al., 2017; McQuown et al., 2019). However, there has been a paucity of research comprehensively assessing the effects of PDE1 inhibitor in animal models relevant to positive and negative symptoms in schizophrenia. In addition, there has been no preclinical evidence demonstrating the efficacy of PDE1 inhibitors in cognitive functions in nonhuman primates (Li et al., 2016a; Snyder et al., 2016; Pekcec et al., 2018). It is important to assess cognitive effects in nonhuman primates with a well-developed prefrontal cortex, since cognitive deficits associated with schizophrenia have been hypothesized to be related to dysfunction of the prefrontal cortex (Lewis and González-Burgos, 2008). In our drug discovery program, we discovered the PDE1 inhibitor 3-methyl-7-(tetrahydro-2H-pyran4-yl)-2-\{[trans-4-(trifluoromethyl)cyclohexyl]-methoxy\}imidazo [5,1-f][1,2,4]triazin-4(3H)-one (DSR-141562), which has preferential selectivity for PDE1B over PDE1A and PDE1C. In the present study, we characterized the preclinical profile of DSR-141562 in pharmacological assays in vitro, and in pharmacokinetic and biomarker studies in vivo. Furthermore, we evaluated the potential of DSR-141562 as a therapeutic candidate in animal models for positive, negative, and cognitive symptoms associated with schizophrenia. In the cognitive function, we used not only a learning and memory task in rats but also an executive function task in common marmosets.

\section{Materials and Methods}

Animals. We used male Institute of Cancer Research (ICR) strain mice (Japan SLC Inc., Shizuoka, Japan, or Clea Japan Inc., Tokyo, Japan), male Sprague-Dawley strain rats (Japan SLC Inc. or Charles River Laboratories Japan, Inc., Yokohama, Japan), and male cynomolgus monkeys (Hamri Co., Ltd., Ibaraki, Japan, or Tian $\mathrm{Hu}$ Cambodia Animal Breeding Research Center Ltd., Kampong Cham, Cambodia), which are commonly used laboratory animals in pharmacology research. However, female Long-Evans rats were used in the novel object recognition task as described previously (Horiguchi et al., 2013), since they are commonly used for this task. In addition, it is known that there are gender differences in the pharmacological actions and pharmacokinetics of phencyclidine (Nabeshima et al., 1984) or cognitive performance in this task (Sutcliffe et al., 2007). We used four male and six female common marmosets (Clea Japan Inc.) in an object retrieval with detour task, as we described previously (Murai et al., 2013; Baba et al., 2015; Kotani et al., 2016), to obtain sufficient numbers of welltrained marmosets. There were no gender differences in the basal performance of this task (our unpublished data). All animals were housed in a controlled environment under a 12/12 hour light/dark cycle with ad libitum access to water. Rodents had free access to food, and nonhuman primates were given food once daily in the morning. All procedures involving the use of animals were reviewed and approved by the Institutional Animal Care and Use Committee of Sumitomo Dainippon Pharma Co., Ltd. (Osaka, Japan) or Shin Nippon Biochemical Laboratories Ltd. (Kagoshima, Japan).

Drugs and Reagents. DSR-141562, methamphetamine hydrochloride, and phencyclidine hydrochloride were prepared by Sumitomo Dainippon Pharma Co., Ltd. 3-Allyl-6-chloro-1-phenyl-2,3,4,5-tetrahydro$1 H$-benzo[d]azepine-7,8-diol hydrobromide (SKF-82958 hydrobromide) was purchased from Sigma-Aldrich (St. Louis, MO). As for the route of DSR-141562 administration, we chose the oral route, which would be a potential route in clinical studies, for pharmacological experiments not involving c-fos expression measurement. DSR-141562 was subcutaneously administered to achieve the high plasma drug concentrations needed for c-fos expression measurement. In the pharmacokinetic experiments, the compounds were orally and intravenously administered to calculate bioavailability. Doses of DSR-141562 were chosen based on the in vitro $\mathrm{IC}_{50}$ value for $\mathrm{PDE} 1 \mathrm{~B}$, our pharmacokinetic results, and results of pilot pharmacological experiments. DSR-141562 was suspended in $0.5 \%(\mathrm{w} / \mathrm{v})$ methylcellulose or $10 \%(\mathrm{w} / \mathrm{v})$ hydroxypropyl- $\beta$-cyclodextrin for oral administration, and dissolved in $40 \%$ (w/v) hydroxypropyl- $\beta$-cyclodextrin for subcutaneous administration or in $0.1 \mathrm{~N}$ hydrochloric acid/saline (1/9) for intravenous administration. Methamphetamine, phencyclidine, and SKF-82958 were dissolved in saline. The dosages of compounds were calculated in terms of the salt form of the compound. Recombinant human PDE1A, PDE1B, and PDE1C enzymes (SB Drug Discovery Ltd., Glasgow, UK), pig brain calmodulin (Enzo Life Sciences, Farmingdale, NY), $\left[{ }^{3} \mathrm{H}\right]$-cGMP (Perkin Elmer, Waltham, MA), and $\mathrm{cAMP}-{ }^{13} \mathrm{C}_{5}$ were purchased from commercial sources.

In Vitro Phosphodiesterase 1A, 1B, and 1C Assays. Inhibition of PDE1A, 1B, and 1C activities was measured by scintillation proximity assays (Glickman et al., 2008). Recombinant human PDE1A, $1 \mathrm{~B}$, and $1 \mathrm{C}$ were used as enzymes, and $\left[{ }^{3} \mathrm{H}\right]-\mathrm{cGMP}$ was used as the substrate. The concentration of each enzyme in the assay solution was $1.3 \mathrm{U} / \mathrm{ml}$ for PDE1A, $3.2 \mathrm{U} / \mathrm{ml}$ for PDE1B, and $1.1 \mathrm{U} / \mathrm{ml}$ for PDE1C. The substrate concentration in the assay solution was $100 \mathrm{nM}$, which is below the enzyme $K_{\mathrm{m}}$ values for cGMP. The reaction 
was allowed to proceed for 30 minutes at $27^{\circ} \mathrm{C}$. The reaction mixture contained $1 \mathrm{mM} \mathrm{CaCl}{ }_{2}$ and $1 \mu \mathrm{g} / \mathrm{ml}$ calmodulin. Assays were independently performed three times on three different days to determine the mean and S.E. (S.E.M) of $\mathrm{IC}_{50}$ values for each PDE isoform.

In Vitro Assays of Other Phosphodiesterase Isoforms. Other PDE isoform assays were conducted by SB Drug Discovery Ltd. Human recombinant PDE2A, PDE3 catalytic domain, PDE4 catalytic domain, PDE5 catalytic domain, PDE7A, PDE8A, PDE9A, PDE10A, and PDE11A were used for IMAP FP assays (Molecular Devices, Sunnyvale, CA). The IMAP FP assay was performed according to the standard protocol of the IMAP bulk assay (Molecular Devices). Fluorescein-labeled cAMP at $100 \mathrm{nM}$ was used as the substrate for PDE2A, PDE3 catalytic domain, PDE4 catalytic domain, PDE7, PDE8, PDE10A, and PDE11A. Fluorescein-labeled cGMP at $100 \mathrm{nM}$ was used as the substrate for PDE5 catalytic domain and PDE9A. Since DSR-141562 at 10,000 nM exhibited more than $50 \%$ of inhibition of PDE2A in our pilot study, the PDE2A inhibition assay was independently performed three times to determine the mean and S.E.M. of $\mathrm{IC}_{50}$ values of DSR-141562. The inhibitory effects of DSR-141562 on other PDE isoforms were measured at $10,000 \mathrm{nM}$, and data were analyzed by calculating the percentage of the inhibition values. Human recombinant PDE6A and PDE6B were used for the radiometric assay (Thompson and Appleman, 1971). $\left[{ }^{3} \mathrm{H}\right]$-cGMP at $1000 \mathrm{nM}$ was used as the substrate. The inhibitory effect of DSR-141562 on PDE6A/B was measured at $10,000 \mathrm{nM}$, and data were analyzed by calculating the percentage of the inhibition value.

In Vitro Off-Target Assays. To evaluate the effects of DSR-141562 at $10,000 \mathrm{nM}$ on the off-targets, Eurofins Pharma Discovery Services (Taipei, Taiwan) performed enzyme and radioligand-binding assays for 65 targets. The information about the assays is available on the Eurofins Discovery Services' website (https://www.eurofinsdiscoveryservices.com/).

Pharmacokinetic Measurement in Animals. For the pharmacokinetic study, DSR-141562 was diluted in $0.1 \mathrm{~N}$ hydrochloric acid/ saline (1/9) for intravenous administration or suspended in $0.5 \%$ methylcellulose for oral administration and administered to male SpragueDawley rats or cynomolgus monkeys at an intravenous dose of $0.5 \mathrm{mg} / \mathrm{kg}$ or oral dose of $1 \mathrm{mg} / \mathrm{kg}$. At 5 (intravenous only), 15 , and 30 minutes, and $1,2,4,6$, and 24 hours after administration, venous blood was collected in sodium heparin. The blood was centrifuged for 15 minutes at $2500 \mathrm{~g}$ at $4^{\circ} \mathrm{C}$ and the resulting plasma was frozen until analyzed.

For the plasma-brain exposure profile pharmacokinetic study, DSR-141562 was suspended in $0.5 \%$ methylcellulose solution and orally administered to male Sprague-Dawley rats at a dose of $30 \mathrm{mg} / \mathrm{kg}$. At $0.5,1,2$, and 6 hours after administration, rats were anesthetized with isoflurane and whole blood was collected in sodium heparin via the inferior vena cava. Plasma was obtained as described previously and frozen until analyzed. Following the blood collection, the brains were removed and stored at freezer temperature until analysis.

To estimate its plasma concentration for pharmacology studies, DSR-141562 was suspended in 0.5\% methylcellulose solution and orally administered to ICR mice at doses of 1 and $30 \mathrm{mg} / \mathrm{kg}$. Two hours after administration, venous blood was collected in sodium heparin. In Sprague-Dawley rats, DSR-141562 was dissolved in 40\% hydroxypropyl$\beta$-cyclodextrin and subcutaneously administered at a dose of $10 \mathrm{mg} / \mathrm{kg}$. One hour after administration, venous blood was collected in sodium heparin. In common marmosets, DSR-141562 was suspended in $0.5 \%$ methylcellulose solution and orally administered at doses of 1 and $10 \mathrm{mg} / \mathrm{kg}$. Two hours after administration, venous blood was collected in sodium heparin. Plasma was obtained as described previously and frozen until analyzed.

The plasma and brain homogenate samples were extracted by protein precipitation with methanol containing an internal standard (phenytoin) and analyzed by means of liquid chromatography-tandem mass spectrometry, using an API 4000 (SCIEX, Framingham, MA) mass spectrometer with electrospray ionization interface in positive ion mode and multiple reactions monitoring. An LC-20A Series HPLC system
(Shimadzu, Kyoto, Japan) was used with a Unison UK-C18 column $(2.0 \times 20 \mathrm{~mm}, 3 \mu \mathrm{m}$; Imtakt Corporation, Kyoto, Japan $)$ at a flow rate of $0.4 \mathrm{ml} / \mathrm{min}$ to achieve chromatographic separation. A gradient program was used with the mobile phase, combining solvent A [ammonium acetate buffer (10 mM, pH 4.0)] and solvent $\mathrm{B}$ (methanol) as follows: $10 \%-90 \% \mathrm{~B}$ for $0-2.5$ minutes, $90 \% \mathrm{~B}$ for $2.5-3.7$ minutes, and $10 \% \mathrm{~B}$ for $3.71-5.5$ minutes. The column temperature was set at $40^{\circ} \mathrm{C}$. The transitions (precursor to product) monitored for mass spectrometry were mass-to-charge ratios (m/z) 415.300-251.200 for DSR-141562 and 253.226-182.225 for phenytoin. Phoenix WinNonlin (Certara, Princeton, NJ) was used for all pharmacokinetic and noncompartmental analyses.

Brain Tissue Cyclic Nucleotide Measurements in Mice. Brain tissue cGMP contents were measured as previously reported with some modifications (Schmidt et al., 2008). Male ICR mice were orally administered vehicle (0.5\% methylcellulose) or DSR-141562 at $10 \mathrm{mg} / \mathrm{kg}$. In the experiments evaluating the combined effects of DSR-141562 and a dopamine $\mathrm{D}_{1}$ receptor agonist, mice were subcutaneously administered saline or SKF-82958 $(0.3 \mathrm{mg} / \mathrm{kg}) 1$ hour after the administration of vehicle or DSR-141562. Two hours after vehicle or DSR-141562 treatment, mice were sacrificed by focused microwave irradiation of the brain. Brain regions of interest were isolated and stored at $-80^{\circ} \mathrm{C}$ until use. Brain tissues were homogenized in $0.1 \mathrm{~N}$ hydrochloric acid followed by centrifugation. Supernatant concentration of cGMP or cAMP were measured using enzyme-linked immunosorbent assay kits (Direct cGMP EIA kit, ADI-900-014; Enzo Life Sciences) and homogeneous time-resolved fluorescence kits (HTRF cAMP Dynamic2; Cisbio Bioassays, Bedford, MA), respectively.

Cerebrospinal Fluid and Plasma Sampling in Monkeys. The cerebrospinal fluid (CSF) sampling was conducted at Shin Nippon Biochemical Laboratories Ltd., as previously described with some modification (Kleiman et al., 2012). Adult cynomolgus monkeys were individually housed in cages $(680 \mathrm{~mm} \times 620 \mathrm{~mm} \times 770 \mathrm{~mm})$ kept in a temperature-controlled $\left(23-29^{\circ} \mathrm{C}\right)$ and humidity-controlled $(30 \%-70 \%)$ animal room. Under anesthesia with ketamine hydrochloride at $10 \mathrm{mg} / \mathrm{kg}$, i.m. (Supriya Lifescience, Mumbai, India), and medetomidine hydrochloride at $0.08 \mathrm{mg} / \mathrm{kg}$, i.m. (Nippon Zenyaku Kogyo, Tokyo, Japan), monkeys were fitted surgically with an indwelling cannula into the cisterna magna, and the cannula was connected to a subcutaneous access port to permit CSF sampling. The animals were administered ketoprofen at $2 \mathrm{~m} / \mathrm{kg}$, i.m. (Kissei, Nagano, Japan), for pain relief once a day on the day of surgery and for the next 3 days. To prevent infection, monkeys were administered benzylpenicillin procaine at 10,000 U/kg and dihydrostreptomycin sulfate at $12.5 \mathrm{mg} / \mathrm{kg}$ (Kyoritsu Seiyaku, Tokyo, Japan) once a day on the day of surgery and for the next 3 days. These antibiotics were administered again 1 day before each CSF sampling on four consecutive days. After the recovery period, DSR-141562 (30 and $100 \mathrm{mg} / \mathrm{kg}$ ) or vehicle (10\% hydroxy$\beta$-cyclodextrin) was orally administered once a week in a crossover manner. The CSF samples were collected from the indwelling cannula before (baseline) or $0.5,1,2,4,6,8$, and 24 hours after the administration. The CSF samples were centrifuged at $600 \mathrm{~g}$ for 10 minutes. The blood samples were collected from the femoral vein into the syringe containing heparin $0.25,0.5,1,2,4,6,8$, and 24 hours after the administration. The plasma samples were separated by centrifugation at $1710 \mathrm{~g}$ for 15 minutes. The CSF and plasma samples were frozen and stored at $-80^{\circ} \mathrm{C}$ for the analysis of cGMP, cAMP, and drug concentrations.

Measurement of Cyclic Nucleotides and DSR-141562 in Monkey CSF or Plasma. The CSF samples mixed with internal standard (cAMP- ${ }^{13} \mathrm{C}_{5}$ ) solution were analyzed by means of liquid chromatography-tandem mass spectrometry, using a QTRAP 6500 (SCIEX) mass spectrometer with electrospray ionization interface in positive ion mode and multiple reactions monitoring. A Nexera $\times 2$ series HPLC system (Shimadzu) was used with a Synergi Hydro RP column $(2.0 \times 50 \mathrm{~mm}, 2.5 \mu \mathrm{m}$; Phenomenex, Torrance, CA $)$ at a flow rate of $0.4 \mathrm{ml} / \mathrm{min}$ to achieve chromatographic separation. A gradient program was used with the mobile phase, combining solvent $\mathrm{A}$ 
[water with $0.1 \%(\mathrm{v} / \mathrm{v})$ formic acid] and solvent B [acetonitrile with $0.1 \%(\mathrm{v} / \mathrm{v})$ formic acid] as follows: $1 \%-7 \% \mathrm{~B}$ for $0-2.5$ minutes, $7 \%-$ $95 \% \mathrm{~B}$ for $2.5-5.0$ minutes, $95 \% \mathrm{~B}$ for $5.0-6.5$ minutes, and $1 \% \mathrm{~B}$ for 6.6-9.0 minutes. The column temperature was set at $40^{\circ} \mathrm{C}$. The transitions (precursor to product) monitored for mass spectrometry were $\mathrm{m} / \mathrm{z}$ 330.1-136.0 for cAMP, 346.2-152.0 for cGMP, and 335.1-119.0 for cAMP- ${ }^{13} \mathrm{C}_{5}$. Relative change of the CSF cyclic nucleotide concentration from baseline in each animal was calculated by correcting with the baseline value obtained before administration with vehicle or DSR-141562 on each experimental day. The plasma concentrations of DSR-141562 were measured as described previously.

Brain Tissue c-fos Expression Measurement in Rats. Brain tissue c-fos expression was measured according to a previous procedure with some modifications (Strick et al., 2010). Male Sprague-Dawley rats were subcutaneously administered with vehicle (40\% hydroxypropyl- $\beta$-cyclodextrin) or DSR-141562 $(3,10$, and $30 \mathrm{mg} / \mathrm{kg}$ ). Sixty minutes later, the rats were sacrificed by decapitation. Frontal cortex, striatum, and cerebellum were dissected out and frozen at $-80^{\circ} \mathrm{C}$ in RNA stabilization solution (RNAlater; Thermo Fisher Scientific Inc., Waltham, MA) until use. Total RNA of each sample was purified using an RNeasy Mini Kit (Qiagen N.V., Venlo, The Netherlands) and quantified with a RiboGreen RNA Quantification Kit (Thermo Fisher Scientific Inc.). Total RNA $(1.0 \mu \mathrm{g})$ was converted into cDNA using a High Capacity cDNA Reverse Transcription Kit (Thermo Fisher Scientific Inc.) according to the manufacturer's instructions. Real-time quantitative polymerase chain reaction was performed in $20 \mu \mathrm{l}$ of reaction solution containing cDNA (50 ng), genespecific primers for c-fos (Rn00487426-g1), 18S rRNA (T Eukaryotic 18S rRNA Endogenous Control), and TaqMan Gene Expression Master Mix (Thermo Fisher Scientific Inc.). The reactions were performed using an Applied Biosystems 7500 Fast Real-Time PCR System [Thermal cycling conditions: $50^{\circ} \mathrm{C}$ for 2 minutes, $95^{\circ} \mathrm{C}$ for 10 minutes, $95^{\circ} \mathrm{C}$ for 15 seconds $(40$ cycles $)$, and $60^{\circ} \mathrm{C}$ for 1 minute]. Data were analyzed by using the $2^{-\Delta \Delta \mathrm{C}(\mathrm{T})}$ method (Livak and Schmittgen, 2001) and normalized to the housekeeping gene, 18S rRNA. Relative change of c-fos expression was calculated by correcting with the average value of the vehicle group.

Locomotor Activity Measurement in Rats. The locomotor activities were measured in male Sprague-Dawley rats as previously described with some modifications (Sumiyoshi et al., 2013). To evaluate the effects of DSR-141562 on spontaneous locomotor activities, rats were orally administered DSR-141562 $(3,10$, and $30 \mathrm{mg} / \mathrm{kg})$ or vehicle $(0.5 \%$ methylcellulose $)$ and returned to their home cages. Sixty minutes later, the rats were individually placed in other cages for locomotor measurement $(220 \mathrm{~mm} \times 380 \mathrm{~mm} \times 205 \mathrm{~mm})$. The locomotor activity was measured for 90 minutes with a Supermex activity measurement apparatus (Muromachi Kikai Co. Ltd., Tokyo, Japan). To evaluate the effect of DSR-141562 on methamphetamineinduced locomotor hyperactivity, rats were orally administered DSR-141562 $(3,10$, and $30 \mathrm{mg} / \mathrm{kg})$ or vehicle, and individually placed in other cages for locomotor measurement. After habituation to the new cage environment for 60 minutes, rats were intraperitoneally injected with methamphetamine $(1 \mathrm{mg} / \mathrm{kg})$. Locomotor activity after methamphetamine administration was measured for 90 minutes.

Catalepsy Test in Rats. The catalepsy test was performed as previously described with some modifications (Ishibashi et al., 2010). Male Sprague-Dawley rats were orally treated with DSR-141562 $(1,10$, and $100 \mathrm{mg} / \mathrm{kg})$ or vehicle ( $0.5 \%$ methylcellulose). One hour later, rats' forepaws were placed on a stainless-steel bar. The time that the animal maintained this position was measured three times, each with a maximum limit of 180 seconds. The maximum of the three measurements was regarded as the catalepsy time.

Social Interaction Test in Mice. The social interaction test was performed as previously reported with some modification (Qiao et al., 2001). ICR mice were subcutaneously administered saline or phencyclidine $(10 \mathrm{mg} / \mathrm{kg}$ ) twice a day for 5 days (excluding weekends). One day after the last administration, mice were habituated to the experimental cages $(400 \mathrm{~mm} \times 250 \mathrm{~mm} \times 300 \mathrm{~mm}$ ) in a dark room (less than 10 lux) for 2 hours. Four mice from the same home cage were habituated together in the same experimental cage. On the next day, the mice were orally treated with vehicle $(0.5 \%$ methylcellulose) or DSR-141562 $(0.3,1$, and $3 \mathrm{mg} / \mathrm{kg})$. One hour and 50 minutes later, the mice were individually placed in experimental cages for 10 minutes. After the habituation, two mice, which had received the same treatment in different home cages, were placed in the same experimental cage. Their behavior was recorded for 10 minutes with an infrared video camera. Social behavior duration was manually measured for each pair of mice. Social behaviors were defined as sniffing and grooming the partner, following, mounting, and crawling under or over the partner. The passive contact (sitting or lying with bodies in contact) was not included in the social interaction.

Novel Object Recognition Task in Rats. The novel object recognition task was performed as previously described with some modifications (Horiguchi et al., 2013). Female Long-Evans rats were intraperitoneally treated with saline or phencyclidine $(3 \mathrm{mg} / \mathrm{kg})$ twice a day for 10 days (excluding weekends). Three days after the last administration, eight or 10 rats were habituated for 1 hour to the experimental cage $(500 \mathrm{~mm} \times 500 \mathrm{~mm} \times 350 \mathrm{~mm})$ without any objects for three consecutive days. Six or 7 days later, the rats received the novel object recognition task. This task consists of a habituation phase, an acquisition trial, a 1-minute intertrial interval, and a retention trial. Rats were orally treated with vehicle ( $0.5 \%$ methylcellulose) or DSR-141562 $(0.3,1$, and $3 \mathrm{mg} / \mathrm{kg}) 60$ minutes before the acquisition trial. Rats were individually habituated to the experimental cage without any objects for 3 minutes, and then allowed to explore two identical objects (glass medium bottles, in which the trunk diameter was $65 \mathrm{~mm}$ and the height was $143 \mathrm{~mm}$ ) for 3 minutes in the acquisition trial. After that, rats were returned to their home cages for 1 minute while one of the two objects was replaced with a novel object (a gold metal can, in which the trunk diameter was $65 \mathrm{~mm}$ and the height was $122 \mathrm{~mm}$ ). Rats were allowed to explore the familiar object and the new object for 3 minutes in the retention trial. Object exploration was defined as animals' sniffing and/or touching the object with the nose. The exploration time of each object in each trial was recorded manually using stopwatches. The discrimination index [(time spent exploring the novel object) - (time spent exploring the familiar object)/(total exploration time)] was calculated for the retention trials. The data from rats that took less than 10 seconds in total to explore during the acquisition trial or a retention trial were excluded from the data analysis.

Object Retrieval with Detour Task in Common Marmosets. Object retrieval with detour task was performed using well-trained male and female marmosets to reach for the reward (a piece of kneaded cake) placed in a clear acrylic box $(4 \mathrm{~cm} \times 4 \mathrm{~cm} \times 4 \mathrm{~cm})$ open only on one side, as previously described (Kotani et al., 2016). Marmosets were tested twice a week: once on a drug-free day and once on a treatment day. The drug treatment tests were performed in a crossover manner with administrations separated by at least 1 week. DSR-141562 $(0.3,3$, and $30 \mathrm{mg} / \mathrm{kg})$ or vehicle $(0.5 \%$ methylcellulose $)$ was orally administered to the animals. Two hours later, the experimenter held a clear acryl box just outside the animal cage with the open side facing left, right, or toward the common marmoset. The positions of the reward in the box were outer edge, inner edge, or deep within the box. Each test session consisted of nine easy trials and eight difficult trials. In the easy trials, the reward was placed on the inner or outer edge of the box with the opening of the box facing left or right from the common marmoset, or inside the box with the opening facing the common marmoset. This enabled the animal to directly reach the reward. In the difficult trial, the reward was placed deep within the box with the opening facing the right or left side of the common marmoset. This arrangement required the animal to make a detour around the box to reach the reward. Reaching the reward without touching any wall of the box within 30 seconds was considered correct. When the common marmoset did not reach the reward within 30 seconds, it was defined as an omission. The performance of each animal in the drug-treated session was compared with that in the drug-free session of nine easy and eight difficult trials 
using the following equation: Change of success rate $=(N$ drug treated $)-(N$ drug free $) \times 100 / 9$ or 8 , where $N$ drug treated represents the rate of correct responses in the drug-treated session, $N$ drug free represents the rate of correct results in the drug-free session, and 9 or 8 represents the rate in the easy or difficult trial, respectively.

Statistical Analysis. Data are expressed as mean \pm S.D. or \pm S.E.M. Data analyses were performed using Stat PreClinica (Takumi Information Technology Inc.) or GraphPad Prism7 (GraphPad Software Inc., La Jolla, CA). For mouse brain cyclic nucleotide measurement, mouse social-interaction test, and rat novel object recognition task, the statistical significance of the difference between two groups was determined by unpaired tests. For mouse brain cyclic nucleotide measurement, rat locomotor activity measurement, rat catalepsy test, mouse social-interaction test, and rat novel object recognition task, the statistical significance of the difference among multiple groups was analyzed by Dunnett's or Tukey's multiple comparisons tests. Brain tissue c-fos expression data were analyzed by two-way ANOVA followed by Dunnett's multiple comparisons test. For monkey CSF cyclic nucleotide measurement, data were analyzed by two-way linear mixed models followed by Dunnett's multiple comparisons test. For the marmoset object retrieval with detour task, data were analyzed by one-way linear mixed models followed by Dunnett's multiple comparisons test.

\section{Results}

In Vitro Profiles of DSR-141562. In our drug discovery program for PDE1B inhibitor, we identified a novel compound, DSR-141562 (Fig. 1). DSR-141562 inhibited human PDE1B in vitro with an $\mathrm{IC}_{50}$ value of $43.9 \mathrm{nM}$ (Table 1). Since the $\mathrm{IC}_{50}$ values of DSR-141562 for human PDE1A and 1C were 97.6 and $431.8 \mathrm{nM}$, respectively, DSR-141562 had a 2.2- and 9.8-fold selectivity for PDE1B over PDE1A and PDE1C (Table 1). DSR141562 had no effect or only weak inhibitory effects for other PDE families. The $\mathrm{IC}_{50}$ value of DSR-141562 for human PDE2A was $2480 \mathrm{nM}$, and DSR-141562 showed less than 50\% inhibition for other PDE families at 10,000 nM (Table 1). The effects of DSR-141562 on 65 off-targets were evaluated in enzyme and radioligand-binding assays at Eurofins Pharma Discovery Services. Although DSR-141562 at 10,000 nM showed 64\% and $51 \%$ inhibition of radioligand binding to melatonin $\mathrm{MT}_{1}$ and $\mathrm{MT}_{2}$ receptors (Supplemental Table 2), the inhibitory effects of DSR-141562 for all of the other 63 targets were less than 50\% (Supplemental Tables 1 and 2).

Pharmacokinetic Profiles of DSR-141562. Plasma concentrations of DSR-141562 were measured after administration of DSR-141562 at $1 \mathrm{mg} / \mathrm{kg}$ p.o. and $0.5 \mathrm{mg} / \mathrm{kg}$ i.v. in rats and cynomolgus monkeys (Fig. 2, A and B). As summarized in Supplemental Table 3, the oral and intravenous pharmacokinetic profiles of DSR-141562 indicated that DSR-141562 was orally bioavailable. To evaluate the brain permeability of DSR-141562, plasma and brain exposures were measured

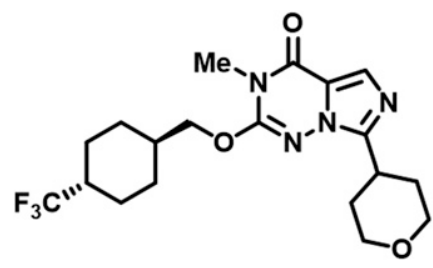

DSR-141562

Fig. 1. The structure of DSR-141562.
TABLE 1

$\mathrm{IC}_{50}$ or inhibitory values of DSR-141562 for human PDEs in vitro Mean \pm S.E.M. $(n=3)$.

\begin{tabular}{lc}
\hline PDE Enzyme & $\mathrm{IC}_{50}$ or Percentage of Inhibition Value \\
\hline PDE1A & $\mathrm{IC}_{50}=97.6 \pm 2.7 \mathrm{nM}$ \\
PDE1B & $\mathrm{IC}_{50}=43.9 \pm 0.4 \mathrm{nM}$ \\
PDE1C & $\mathrm{IC}_{50}=431.8 \pm 11.2 \mathrm{nM}$ \\
PDE2A & $\mathrm{IC}_{50}=2480 \pm 250 \mathrm{nM}$ \\
PDE3 catalytic domain & $44.8 \% \pm 1.08 \%$ at $10,000 \mathrm{nM}$ \\
PDE4 catalytic domain & $9.05 \% \pm 6.17 \%$ at $10,000 \mathrm{nM}$ \\
PDE5 catalytic domain & $-3.23 \% \pm 6.39 \%$ at $10,000 \mathrm{nM}$ \\
PDE6A/B & $-2.66 \% \pm 2.01 \%$ at $10,000 \mathrm{nM}$ \\
PDE7A & $2.19 \% \pm 1.69 \%$ at $10,000 \mathrm{nM}$ \\
PDE8A & $6.98 \% \pm 5.58 \%$ at $10,000 \mathrm{nM}$ \\
PDE9A & $-19.6 \% \pm 27.7 \%$ at $10,000 \mathrm{nM}$ \\
PDE10A & $42.9 \% \pm 4.94 \%$ at $10,000 \mathrm{nM}$ \\
PDE11A & $34.1 \% \pm 1.88 \%$ at $10,000 \mathrm{nM}$ \\
\hline
\end{tabular}

$0.5,1,2$, and 3 hours after the oral administration of DSR141562 at $30 \mathrm{mg} / \mathrm{kg}$ in rats. DSR-141562 exhibited good brain uptake, with the brain-to-blood concentration ratio of unbound drug being 0.99 in rats (Fig. $2 \mathrm{C}$ ). The plasma drug concentrations of this compound for estimating the exposure in pharmacology studies in mice (p.o.), rats (s.c.), and common marmosets (p.o.) are shown in Supplemental Table 4.

Effects of DSR-141562 on Cyclic Nucleotide Contents In Vivo. To evaluate the effects of DSR-141562 on cyclic nucleotide levels, the cyclic nucleotide concentrations were measured in the mouse striatum and frontal cortex 2 hours after oral administration of DSR-141562. Compared with vehicle, DSR-141562 at $10 \mathrm{mg} / \mathrm{kg}$ p.o. slightly but significantly increased cGMP contents in the frontal cortex $(P<0.05)$ (Fig. 3A) and striatum $(P<0.01)$ (Fig. 3B). On the other hand, DSR-141562 did not affect the cAMP content in both brain regions (Supplemental Fig. 1, A and B). To evaluate the effect of DSR-141562 on dopamine $\mathrm{D}_{1}$ receptor signaling, mice were administered DSR-141562 and/or the dopamine $\mathrm{D}_{1}$ receptor agonist SKF-82958. Cotreatment with DSR-141562 and SKF-82958 significantly increased the striatal cGMP level compared with treatment with DSR-141562 and saline $(P<$ $0.01)$ (Fig. 3C) or vehicle and SKF-82958 $(P<0.01)$ (Fig. 3C). The treatment with DSR-141562 and/or SKF-82958 did not affect the striatal cAMP level (Supplemental Fig. 1C).

Next, we evaluated the possibility that the cGMP level in the CSF is a translational biomarker. When cynomolgus monkeys were orally treated with DSR-141562 at 30 and $100 \mathrm{mg} / \mathrm{kg}$, the plasma concentrations of unbound DSR-141562 were above the $\mathrm{IC}_{50}$ values of DSR-141562 for PDE1B in vitro (43.9 nM) (Fig. 4A). DSR-141562 at $30 \mathrm{mg} / \mathrm{kg}$ and $100 \mathrm{mg} / \mathrm{kg}$ (compared with vehicle) caused a significant increase in cGMP concentration in monkey CSF $(P<0.01)$ (Fig. 4B). On the other hand, DSR-141562 (compared with vehicle) induced only a marginal increase in cAMP in monkey $\mathrm{CSF}(P<0.01$ at $30 \mathrm{mg} / \mathrm{kg}$ and $P=0.078$ at $100 \mathrm{mg} / \mathrm{kg}$ ) (Fig. 4C).

Effects of DSR-141562 on c-fos Expression in Rat Brains. To evaluate the effects of DSR-141562 on neuronal activity, we measured the early immediate gene c-fos mRNA expression level in rat brain. When rats were treated with vehicle or DSR-141562 (3, 10, and $30 \mathrm{mg} / \mathrm{kg}$ s.c.), DSR-141562 at 10 and $30 \mathrm{mg} / \mathrm{kg}$ (compared with vehicle) significantly increased the c-fos mRNA expression level in the striatum $(P<0.01)$ (Fig. 5), but not in the frontal cortex and cerebellum (Fig. 5). 
A

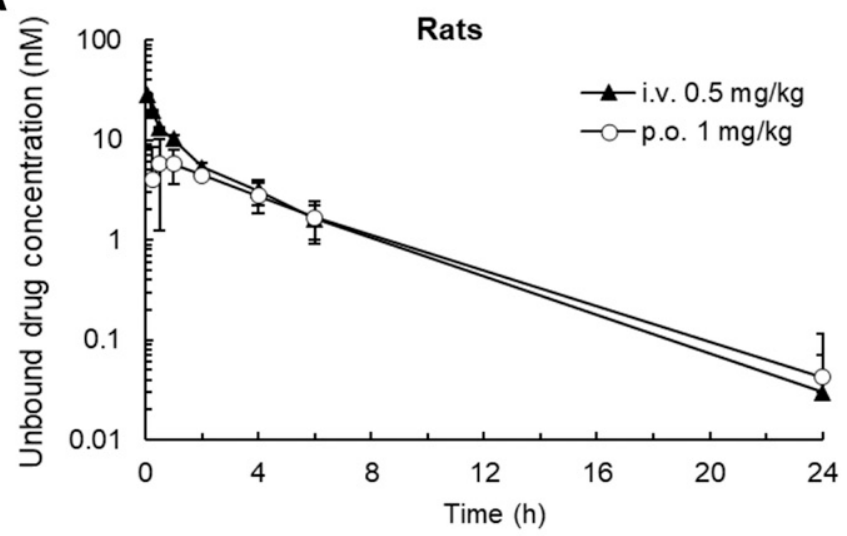

B

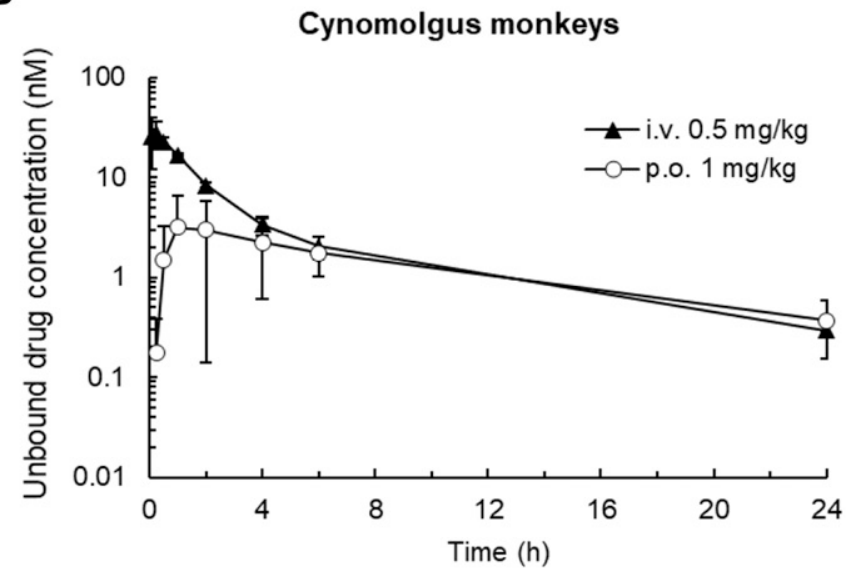

C

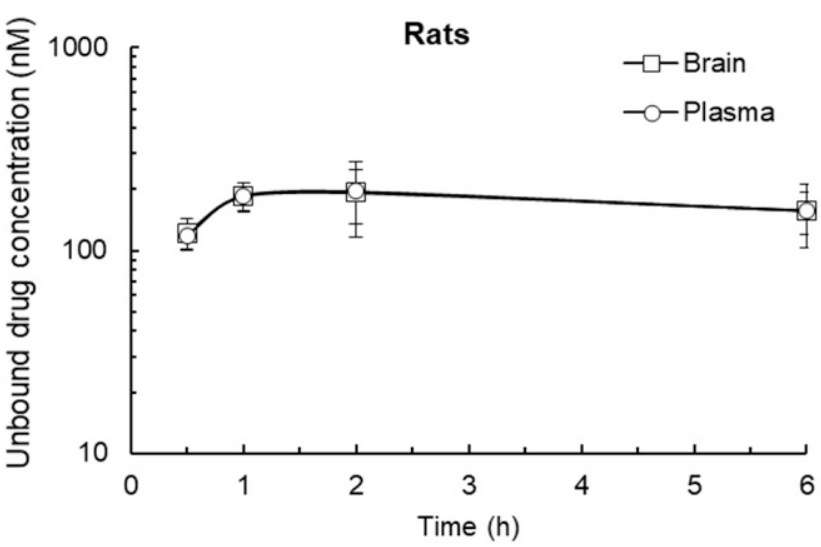

Fig. 2. Plasma concentrations of DSR-141562 in rats and cynomolgus monkeys. DSR-141562 was diluted in $0.1 \mathrm{~N}$ hydrochloric acid/saline (1/9) for intravenous administration or suspended in $0.5 \%$ methylcellulose for oral administration. Rats (A) and cynomolgus monkeys (B) were treated with DSR-141562 at an oral dose of $1 \mathrm{mg} / \mathrm{kg}$ or intravenous dose of $0.5 \mathrm{mg} / \mathrm{kg}$. Plasma samples were collected $0.083,0.25,0.5,1,2,4,6$, and 24 hours after administration. For the plasma-brain exposure profile pharmacokinetic study in rats (C), rats were orally treated with DSR141562 at $30 \mathrm{mg} / \mathrm{kg}$. Plasma and brain samples were collected $0.5,1,2$, and 6 hours after administration. Unbound drug concentration was measured in the samples. Data are expressed as mean \pm S.D. $(n=3$ for oral administration and $n=2$ for intravenous administration).

Behavioral Effects of DSR-141562. We evaluated the effects of DSR-141562 on methamphetamine-induced locomotor hyperactivity in rats using a behavioral assay of antipsychotic efficacy (Jones et al., 2008; Ishibashi et al., 2010).
A

Frontal cortex

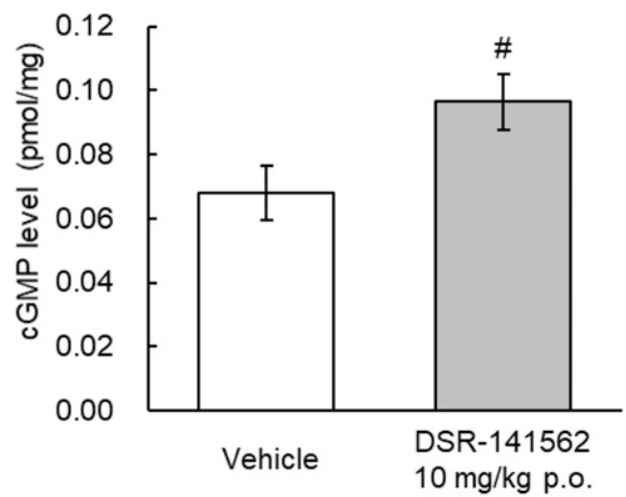

B

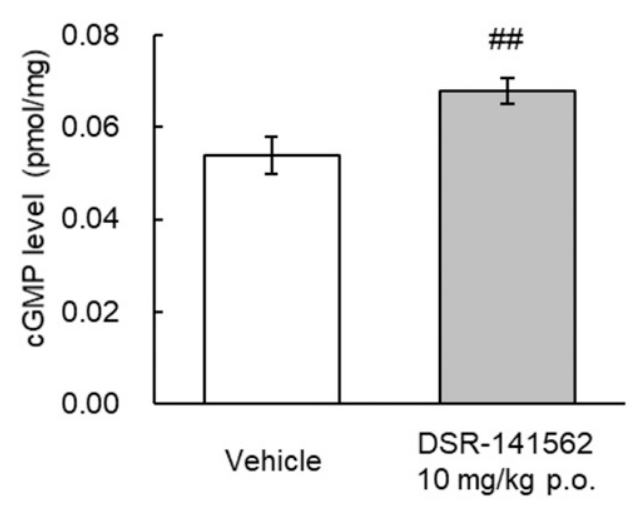

C

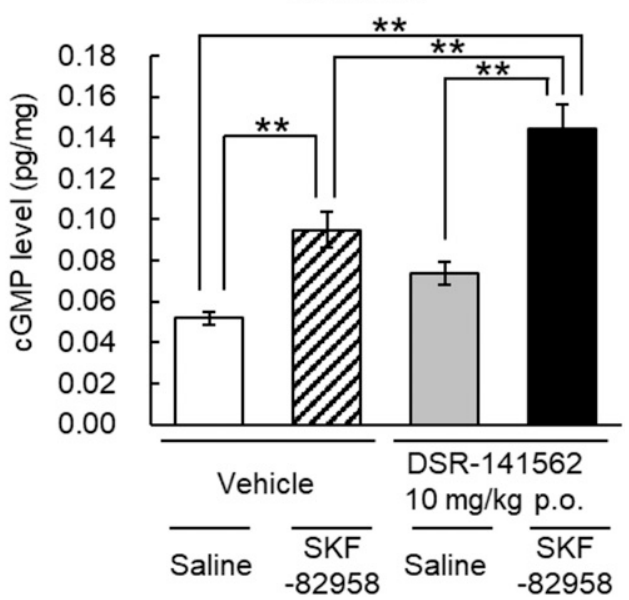

Fig. 3. Effects of DSR-141562 on cGMP concentration in mouse brain tissues. Mice were orally administered vehicle $(0.5 \%$ methylcellulose) or DSR-141562 (10 mg/kg) 120 minutes before brain tissue sampling. In the experiments for the combined effects of DSR-141562 and a dopamine $\mathrm{D}_{1}$ agonist (C), mice were subcutaneously administered saline or SKF-82958 $(0.3 \mathrm{mg} / \mathrm{kg}) 1$ hour after the administration of vehicle or DSR-141562. cGMP levels in the striatum (A and $\mathrm{C}$ ) and frontal cortex (B) were measured by the enzyme-linked immunosorbent assay. Data are expressed as mean \pm S.E.M. The number of animals per group was 15 (A and B). The number of animals in the vehicle/saline-, vehicle/SKF-82958 -, DSR-141562/saline-, and DSR-141562/SKF-82958-treated groups was $12,10,11$, and 11, respectively (C). ${ }^{\#} P<0.05 ;{ }^{\# \#} P<0.01$ vs. vehicle-treated group (unpaired $t$ test). ${ }^{* *} P<0.01$ (Tukey's multiple comparisons test).

DSR-141562 significantly reversed methamphetamine-induced locomotor hyperactivity $(P<0.05$ at $3 \mathrm{mg} / \mathrm{kg}$, and $P<0.01$ at 10 and $30 \mathrm{mg} / \mathrm{kg}$ p.o.) (Fig. 6A), had no effect on spontaneous 


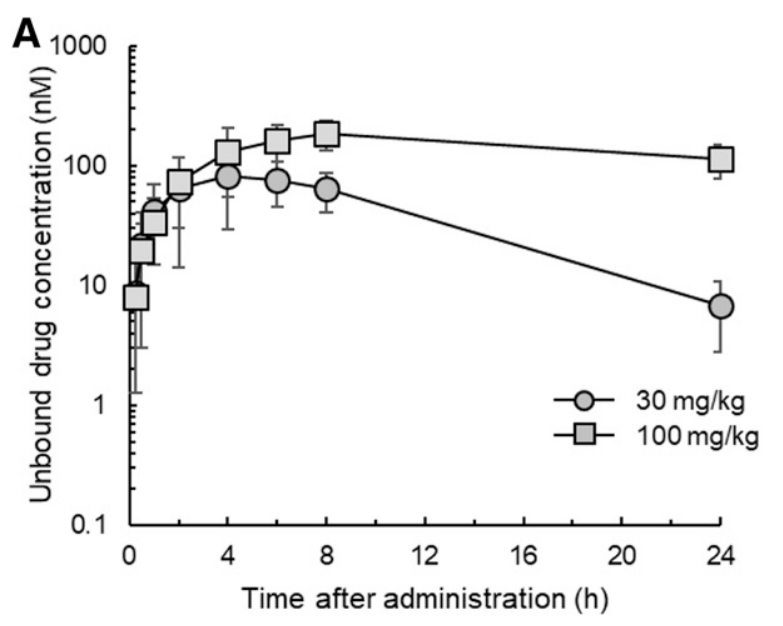

B

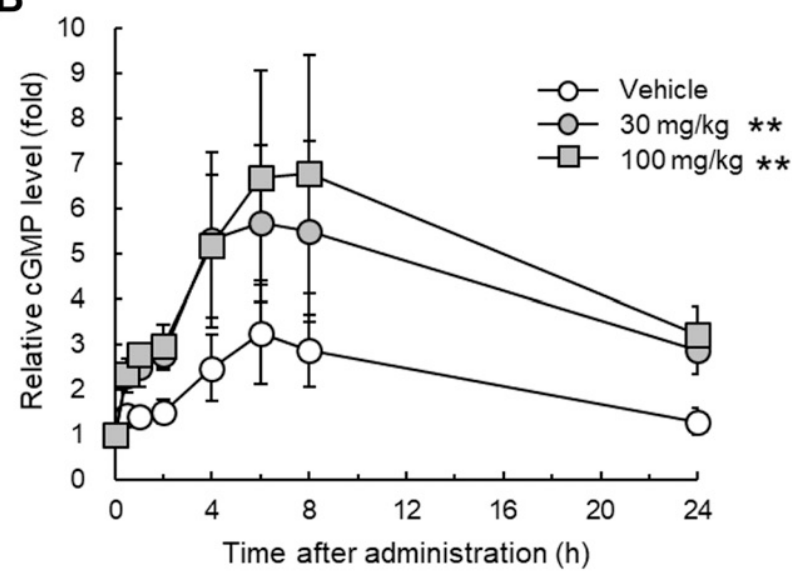

C

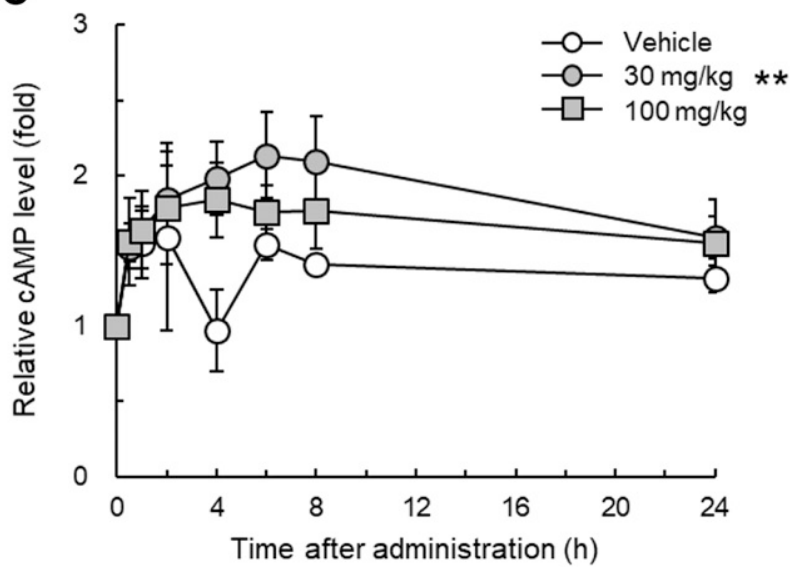

Fig. 4. Effects of DSR-141562 on cyclic nucleotide concentrations in monkey CSF. Cynomolgus monkeys were orally treated with vehicle (10\% hydroxy- $\beta$-cyclodextrin) or DSR-141562 (30 and $100 \mathrm{mg} / \mathrm{kg})$ once a week in a crossover manner. The CSF samples were collected before (baseline) or $0.5,1,2,4,6,8$, and 24 hours after the administration. The blood samples were collected $0.25,0.5,1,2,4,6,8$, and 24 hours after the administration. The unbound drug concentrations in plasma (A) and the cGMP (B) and cAMP (C) concentrations in CSF were measured. The plasma drug concentrations are expressed as mean \pm S.D. Change in CSF cyclic nucleotide concentration from baseline is expressed as mean \pm S.E.M. The number of animals per group was four. ${ }^{* * P}<0.01$ vs. vehicle-treated group (two-way linear mixed models followed by Dunnett's multiple comparisons test).

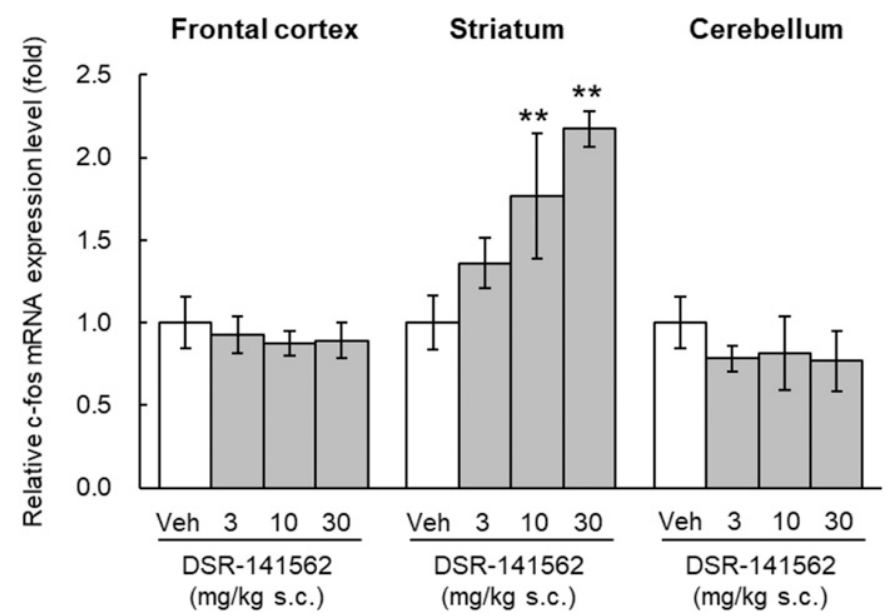

Fig. 5. Effects of DSR-141562 on c-fos mRNA expression in rats. Rats were subcutaneously administered vehicle ( $40 \%$ hydroxy- $\beta$-cyclodextrin) or DSR-141562 $(3,10$, and $30 \mathrm{mg} / \mathrm{kg}) 60$ minutes before brain tissue sampling. The c-fos mRNA expression was measured by the real-time polymerase chain reaction method in the frontal cortex, striatum, and cerebellum. The c-fos mRNA expression level relative to the control level after vehicle treatment in each brain region is expressed as mean \pm S.E.M. The number of animals per group was five. Veh, vehicle. ${ }^{* *} P<$ 0.01 vs. vehicle-treated group (two-way ANOVA followed by Dunnett's multiple comparisons test).

locomotor activity at 3 and $10 \mathrm{mg} / \mathrm{kg}$ (Fig. 6B), and showed a nonsignificant decrease of spontaneous locomotor activity only at the high dose $(30 \mathrm{mg} / \mathrm{kg}$ p.o.; $P=0.08)$ (Fig. 6B).

Next, the potential of DSR-141562 on extrapyramidal side effects was evaluated using the rat catalepsy test. DSR-141562 at 1,10 , and $100 \mathrm{mg} / \mathrm{kg}$ did not cause catalepsy. The catalepsy times in the vehicle-treated and DSR-141562-treated groups at 1,10 , and $100 \mathrm{mg} / \mathrm{kg}$ were $1.8 \pm 0.6,2.0 \pm 0.9,4.9 \pm 2.2$, and $2.6 \pm 0.8$ seconds, respectively (mean \pm S.E.M., $n=6$ ).

We evaluated the effects of DSR-141562 on the decrease of social interaction time in mice induced by repeated treatment with the $N$-methyl-D-aspartate receptor antagonist, phencyclidine, which has been used as a preclinical model for negative symptoms in schizophrenia (Sams-Dodd, 1999; Qiao et al., 2001; Enomoto et al., 2007). Repeated treatment with phencyclidine $(10 \mathrm{mg} / \mathrm{kg}$ s.c., twice a day for 5 days $)$ significantly decreased the social interaction time compared with repeated treatment with saline $(P<0.01)$ (Fig. 7). Compared with vehicle, DSR-141562 significantly reversed the phencyclidine-induced decrease of social interaction time in mice $(P<0.05$ at $0.3 \mathrm{mg} / \mathrm{kg}$, and $P<0.01$ at 1 and $3 \mathrm{mg} / \mathrm{kgp} .0$. .) (Fig. 7).

To evaluate the effects of DSR-141562 on cognitive function, we performed the novel object recognition task in subchronic phencyclidine-treated rats and the object retrieval with detour task in common marmosets. Repeated treatment with phencyclidine $(3 \mathrm{mg} / \mathrm{kg}$ i.p., twice a day for 10 days) decreased the discrimination index compared with repeated treatment with saline $(P<0.01)$ (Fig. 8). DSR141562 at $0.3,1$, and $3 \mathrm{mg} / \mathrm{kg}$ p.o. reversed the decrease of the discrimination index induced by repeated phencyclidine $(P<0.01)$ (Fig. 8). In the object retrieval with detour task, DSR-141562 (0.3, 3, and $30 \mathrm{mg} / \mathrm{kg}$ p.o.) did not affect the success rate in the easy trials (data not shown). On the 
A

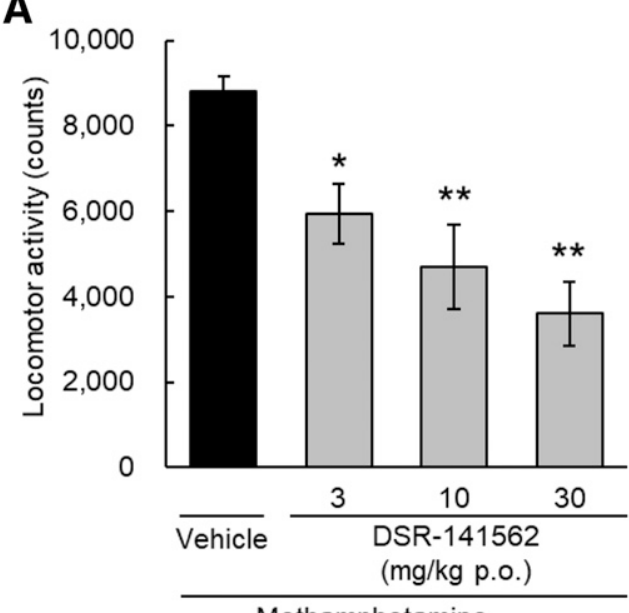

B

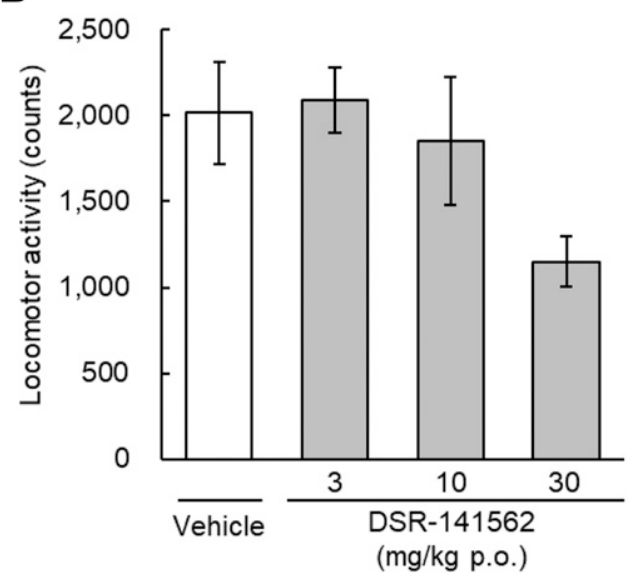

Fig. 6. Effects of DSR-141562 on locomotor activity in rats. Rats were orally treated with vehicle $(0.5 \%$ methylcellulose $)$ or DSR-141562 $(3,10$, and $30 \mathrm{mg} / \mathrm{kg})$. Sixty minutes later, methamphetamine $(1 \mathrm{mg} / \mathrm{kg}$, i.p.)induced locomotor hyperactivity (A) or spontaneous locomotor activity (B) was measured for 90 minutes. Data are expressed as mean \pm S.E.M. $(n=$ 6). ${ }^{*} P<0.05$; $* * P<0.01$ vs. vehicle/methamphetamine-treated group (Dunnett's multiple comparisons test)

other hand, DSR-141562 at 3 and $30 \mathrm{mg} / \mathrm{kg}$ significantly improved the success rate compared with vehicle in the difficult trials $(P<0.01)$ (Fig. 9).

\section{Discussion}

Here, we report that the PDE1 inhibitor DSR-141562 has efficacy in animal models for all three major symptoms in schizophrenia. As far as we know, this is the first paper to show that the PDE1 inhibitor is efficacious in animal models of schizophrenia-associated positive and negative symptoms. Furthermore, it provides the first evidence that the PDE1 inhibitor improves cognitive function in nonhuman primates.

Although PDE1, especially PDE1B, is believed to be an attractive treatment target for neuropsychiatric disorders, the research has been hampered by the shortage of brainpenetrant compounds with PDE1B selectivity. DSR-141562 has remarkable brain permeability with a brain-to-blood unbound drug concentration ratio of 0.99 . While the $\mathrm{IC}_{50}$ value of DSR-141562 for PDE1B is $43.9 \mathrm{nM}$, it acts on other PDE families and other tested targets only in the micromolar

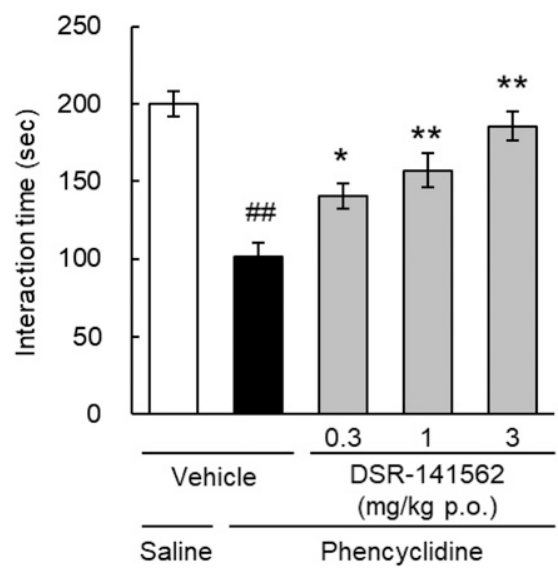

Fig. 7. Effects of DSR-141562 on phencyclidine-induced decrease of social interaction time in mice. Mice were repeatedly treated with saline or phencyclidine $(10 \mathrm{mg} / \mathrm{kg}$ s.c., twice a day for 5 days $)$. Two days after the last administration of saline or phencyclidine, mice were acutely treated with vehicle ( $0.5 \%$ methylcellulose) or DSR-141562 $(0.3,1$, and $3 \mathrm{mg} / \mathrm{kg}$ p.o.). Two hours later, social interaction time between two mice, which received the same treatment in different home cages, was measured for 10 minutes. Data are expressed as mean \pm S.E.M. $(n=16) .{ }^{\# \#} P<0.01$ vs. vehicle/saline-treated group (unpaired $t$ test). ${ }^{*} P<0.05 ; * * P<0.01$ vs. vehicle/phencyclidine-treated group (Dunnett's multiple comparisons test).

range or above. Furthermore, this compound has approximately 2-10 times selectivity for the PDE1B isoform over other PDE1 family isoforms.

DSR-141562 elevated the tissue level of cGMP in mouse striatum and frontal cortex. Furthermore, the cGMP level in the monkey CSF was also elevated after administration of DSR-141562. Cyclic nucleotide concentration has been used as a biomarker in preclinical and clinical studies with PDE9A inhibitors (Kleiman et al., 2012; Boland et al., 2017). Taken together, the data suggest that cGMP in the CSF might be a valuable translational biomarker to detect PDE1 inhibition in the brain. On the other hand, this compound did not elevate the cAMP level in mouse brain tissues, and only marginally increased the cAMP level in monkey CSF. This suggests that cAMP in CSF might not be the most reliable biomarker for PDE1 inhibition. The efficacy of PDE1 inhibition for increasing cAMP levels in brain homogenates might be masked by the high cAMP baseline (Chen et al., 2019). In addition, it might be related to the fact that PDE1B and PDE1A enzymes prefer $\operatorname{cGMP}\left(K_{\mathrm{m}}=1.2-5.9 \mu \mathrm{M}\right.$ for PDE1B; $K_{\mathrm{m}}=2.6-3.5 \mu \mathrm{M}$ for PDE1A) to cAMP $\left(K_{\mathrm{m}}=10-24 \mu \mathrm{M}\right.$ for PDE1B; $K_{\mathrm{m}}=$ 72.7-124 $\mu \mathrm{M}$ for PDE1A) (Bender and Beavo, 2006). However, it is worth mentioning that the brain's cyclic nucleotide content is not a highly sensitive indicator, especially considering the on-demand nature of PDE1 enzyme activation by phasic $\mathrm{Ca}^{2+}$ influx (Grauer et al., 2009; Wennogle et al., 2017; Pekcec et al., 2018; Betolngar et al., 2019). Strick et al. (2010) have reported that immediate early gene c-fos expression is regulated by the cAMP pathway but not the cGMP pathways after administration of an inhibitor of PDE10A, which is another striatum-enriched dual-substrate PDE isoform. When we assessed neural activity by measuring c-fos mRNA expression, DSR-141562 elevated the c-fos expression level in the rat striatum but not the frontal cortex and cerebellum. PDE1B is one of the most robustly expressed enzymes in the striatum among PDEs, and its striatal expression is relatively high compared with the expression of PDE1 isoforms in other brain regions (Lakics et al., 2010; Kelly et al., 2014). Thus, 


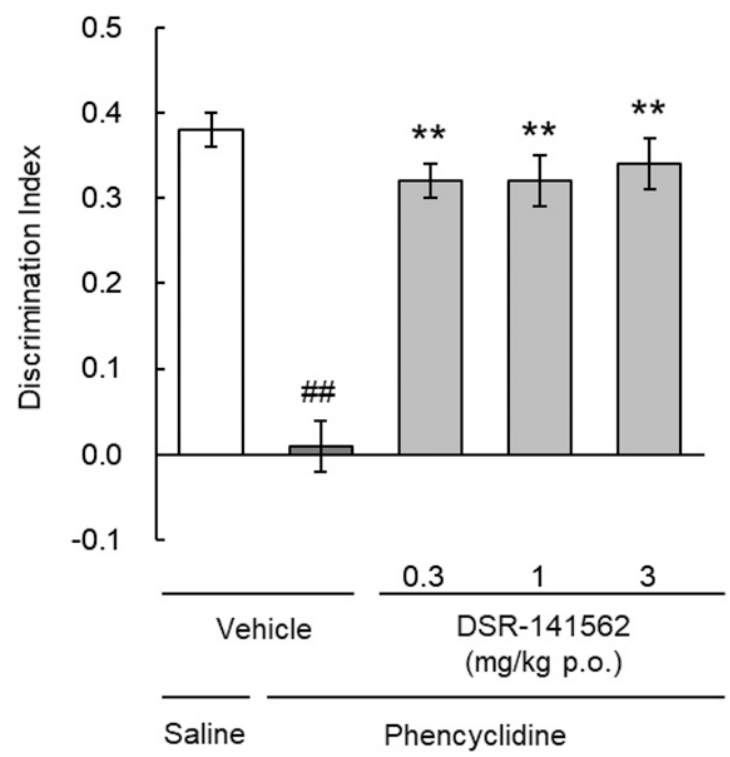

Fig. 8. Effects of DSR-141562 on phencyclidine-induced learning and memory impairments in the rat novel object recognition test. Rats were repeatedly treated with saline or phencyclidine $(3 \mathrm{mg} / \mathrm{kg}$ i.p., twice a day for 10 days). Eleven or 12 days after the last administration with saline or phencyclidine, rats were acutely treated with vehicle ( $0.5 \%$ methylcellulose) or DSR-141562 (0.3, 1, and $3 \mathrm{mg} / \mathrm{kg}$ p.o.). One hour later, the novel object recognition task was performed. The discrimination index [(time spent exploring the novel object) - (time spent exploring the familiar object)/(total exploration time)] was measured. Data are expressed as mean \pm S.E.M. ( $n=14$ for vehicle/phencyclidine-treated and DSR-141562 at $0.3 \mathrm{mg} / \mathrm{kg} /$ phencyclidine-treated groups, $n=15$ for other groups). ${ }^{\# \#} P<0.01 \mathrm{vs}$. vehicle/saline-treated group (unpaired $t$ test). ${ }^{*} P P<0.01 \mathrm{vs}$. vehicle/ phencyclidine-treated group (Dunnett's multiple comparisons test).

DSR-141562 might affect the cAMP downstream signaling pathway at least in the striatum where PDE1B is predominantly expressed.

In the present study, we found that DSR-141562 at $3-30 \mathrm{mg} / \mathrm{kg}$ inhibits methamphetamine-induced locomotor hyperactivity in rats, which has been widely used as a preclinical behavioral assay system for antipsychotic activity (Jones et al., 2008; Ishibashi et al., 2010). Importantly, the effective dose of DSR-141562 in this antipsychotic test has only minimal effects on spontaneous locomotor activity, which indicates that the effects of DSR-145162 cannot be attributed to general sedation or motor deficits. These findings are somewhat surprising since previous studies have demonstrated that PDE1B-deficient mice exhibit increased spontaneous locomotor activity and exaggerated methamphetamine- or amphetamine-induced locomotor hyperactivity (Reed et al., 2002; Siuciak et al., 2007). We recognize that current experimental results cannot exclude the possibility that PDE1A, PDE1C, or other untested pharmacological targets of DSR141562 or its metabolites might have antipsychotic effects, although DSR-141562 has a high selectivity for PDE1 family isoforms among our tested targets, which include potential antipsychotic targets (Nishi and Snyder, 2010; Girgis et al., 2019). However, sometimes the discrepancies in the behavioral phenotype of genetically manipulated mice and in the pharmacological effects of compounds are due to compensatory changes during development (Hufgard et al., 2017a). For example, PDE1B-deletion mice manifest a compensatory increase in PDE10A in the striatum (Hufgard et al., 2017a). In addition, the immobility-resistant phenotype of PDE1B-deficient

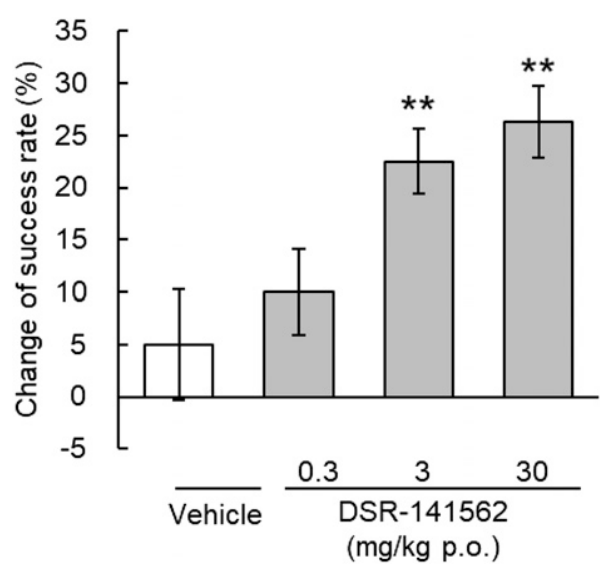

Fig. 9. Effects of DSR-141562 on executive function in common marmosets. Marmosets were orally treated with vehicle $(0.5 \%$ methylcellulose) or DSR-141562 $(0.3,3$, and $30 \mathrm{mg} / \mathrm{kg}) 2$ hours before the object retrieval with detour task. The test was performed in a crossover manner with administrations separated by at least 1 week. The change in success rate from the baseline performance was measured in the difficult trials. Data are expressed as mean \pm S.E.M. $(n=10)$. $* * P<0.01$ vs. vehicletreated group (linear mixed model followed by Dunnett's multiple comparisons test)

mice is detected when the PDE1B gene deletion occurs during postnatal days 0 or 32 but not during adulthood (Hufgard et al., 2017b). Furthermore, PDE1B-deficient mice display spatial learning and memory impairments in the Morris water maze task (Reed et al., 2002), while PDE1 inhibitors improve learning and memory function in several behavioral tasks in mice and rats (Li et al., 2016a; Snyder et al., 2016; Pekcec et al., 2018; McQuown et al., 2019). It is worth mentioning that PDE1B is expressed not only in $\mathrm{D}_{1}$ receptor-expressing but also $\mathrm{D}_{2}$ receptor-expressing medium spiny neurons, which are targets of current antipsychotics (Polli and Kincaid, 1994; Yan et al., 1994; Nishi and Snyder, 2010). The regulation of $\mathrm{D}_{2}$ receptor downstream signaling by DSR141562 might be involved in its antipsychotic efficacy. Indeed, Betolngar et al. (2019) have reported that PDE1 inhibitor suppresses the $N$-methyl-D-aspartate-induced decrease in cAMP not only in $\mathrm{D}_{1}$ receptor-expressing but also $D_{2}$ receptor-expressing striatal neurons in vitro. Thus, the antipsychotic mechanism of DSR-141562, especially the contribution of the $\mathrm{D}_{2}$ receptor-expressing indirect pathway, remains to be evaluated.

Most current antipsychotics induce catalepsy at near effective doses in antipsychotic behavioral assays (Ishibashi et al., 2010). DSR-141562 does not induce any sign of catalepsy at even $100 \mathrm{mg} / \mathrm{kg}$, which is a 33-times higher dose than the effective dose on methamphetamine-induced locomotor hyperactivity. This is quite in contrast to the concept that antipsychotic candidate PDE10A inhibitors typically operate within a narrow dose range because of extrapyramidal side effects in mice, rats, monkeys, and humans (Schmidt et al., 2008; Grauer et al., 2009; Uthayathas et al., 2014; Li et al., $2016 \mathrm{~b}$; Goldsmith et al., 2017). Since the extrapyramidal side effects were dose limiting in clinical studies with $\mathrm{D}_{2}$ receptor antagonists and PDE10A inhibitors, the wide safety margin of the DSR-141562 dose for catalepsy would be of great benefit in schizophrenia treatment.

Since phencyclidine is known to mimic schizophrenia-like symptoms in humans including positive, negative, and 
cognitive symptoms (Javitt and Zukin, 1991), it has been widely used in animals to model schizophrenia, especially its negative and cognitive symptoms (Jentsch and Roth, 1999; Sams-Dodd, 1999; Enomoto et al., 2007). The present study demonstrated that DSR-141562 reversed the decrease of social interaction time in mice repeatedly injected with phencyclidine, which is an animal model for negative symptoms. In addition, we found that DSR-141562 reversed learning and memory impairments in rats repeatedly injected with phencyclidine. Furthermore, we assessed the effects of DSR-141562 in common marmosets, which have a well-developed prefrontal cortex (Lewis and González-Burgos, 2008), since the pathophysiology of schizophrenia has been thought to involve the prefrontal cortex (Marvanová et al., 2003; Kaiser and Feng, 2015). The object retrieval with detour task is a behavioral test for the attentional and inhibitory aspects of executive function, which is dependent on the prefrontal cortex (Diamond et al., 1989; Wilkinson et al., 1997; Wallis et al., 2001). We have previously reported that most antipsychotics have detrimental effects or no beneficial effects on executive function in this task (Murai et al., 2013; Baba et al., 2015). On the other hand, DSR-141562 potently improved executive function in marmosets in the present study, which suggests that this compound has great potential as a cognitive enhancer.

The dopamine $D_{1}$ receptor is expected to be an attractive target for the development of agonists that are effective against schizophrenia-associated negative and cognitive symptoms (Goldman-Rakic et al., 2004; Remington et al., 2011). However, dopamine $D_{1}$ receptor agonism has peripheral side effects such as hypotension, which has hampered the clinical development of agonists for these indications (Arnsten et al., 2017). PDE1B enzymes are colocalized with $D_{1}$ receptors in the striatum and prefrontal cortex (Polli and Kincaid, 1994; Yan et al., 1994; Pekcec et al., 2018), and mainly based on research with genetically manipulated animals it has been hypothesized that PDE1B inhibition augments downstream $\mathrm{D}_{1}$ receptor signaling (Reed et al., 2002; Nishi and Snyder, 2010). We found that DSR-141562 enhanced the increase of cGMP induced by a dopamine $\mathrm{D}_{1}$ receptor agonist. Although the physiological roles of the $\mathrm{D}_{1}$ receptor agonist-induced cGMP pathway are relatively unknown compared with the traditional cAMP pathway (Altar et al., 1990; Snyder and Vanover, 2014), cGMP signaling has recently attracted a great deal of attention as a therapeutic target for schizophreniaassociated negative and cognitive symptoms (Reneerkens et al., 2009; Shim et al., 2016). DSR-141562-induced augmentation of $\mathrm{D}_{1}$ receptor signaling might be related to its efficacy for negative and cognitive symptoms.

In summary, we identified the orally-available and brainpenetrating PDE1 inhibitor DSR-141562. Since DSR-141562 exhibits potent efficacy in animal models for positive, negative, and cognitive symptoms associated with schizophrenia, this compound could have great potential as a novel therapeutic agent for schizophrenia.

\section{Acknowledgments}

We express our appreciation to Akemi Nishihara, Hiroko Ikeda, Yuji Yasuda, Yuji Ogi, Tatsuo Nakayama, and Tomokazu Nakako for technical expertise, and Nobuyuki Yamaguchi, Tatsuya Ishikawa, Junji Ichihara, Kumiko Ishida, and Hiroyuki Nishikawa for helpful discussions.

\section{Authorship Contributions}

Participated in research design: Enomoto, Nishizato, Nishigori, Kitamura, Hashimoto.

Conducted experiments: Enomoto, Tatara, Goda, Nishizato, Nishigori,

Kamada, Taga, Ikeda.

Contributed new reagents or analytic tools: Fujii.

Performed data analysis: Enomoto, Nishizato, Nishigori, Kitamura.

Wrote or contributed to the writing of the manuscript: Enomoto, Nishigori, Kitamura, Kamada.

\section{References}

Altar CA, Boyar WC, and Kim HS (1990) Discriminatory roles for $\mathrm{D}_{1}$ and $\mathrm{D}_{2}$ dopamine receptor subtypes in the in vivo control of neostriatal cyclic GMP. Eur $J$ Pharmacol 181:17-21.

Arnsten AF, Girgis RR, Gray DL, and Mailman RB (2017) Novel dopamine therapeutics for cognitive deficits in schizophrenia. Biol Psychiatry 81:67-77.

Baba S, Murai T, Nakako T, Enomoto T, Ono M, Shimizu I, and Ikeda K (2015) The serotonin $5-\mathrm{HT}_{1 \mathrm{~A}}$ receptor agonist tandospirone improves executive function in common marmosets. Behav Brain Res 287:120-126.

Bender AT and Beavo JA (2006) Cyclic nucleotide phosphodiesterases: molecular regulation to clinical use. Pharmacol Rev 58:488-520.

Betolngar DB, Mota É, Fabritius A, Nielsen J, Hougaard C, Christoffersen CT, Yang J, Kehler J, Griesbeck O, Castro LRV, et al. (2019) Phosphodiesterase 1 bridges glutamate inputs with NO- and dopamine-induced cyclic nucleotide signals in the striatum. Cereb Cortex DOI: 10.1093/cercor/bhz041 [published ahead of print].

Boland K, Moschetti V, Dansirikul C, Pichereau S, Gheyle L, Runge F, ZimdahlGelling H, and Sand M (2017) A phase I, randomized, proof-of-clinical-mechanism study assessing the pharmacokinetics and pharmacodynamics of the oral PDE9A inhibitor BI 409306 in healthy male volunteers. Hum Psychopharmacol 32:e2569.

Carlsson A, Hansson LO, Waters N, and Carlsson ML (1999) A glutamatergic deficiency model of schizophrenia. Br J Psychiatry Suppl 37:2-6.

Casey DE (1996) Extrapyramidal syndromes and new antipsychotic drugs: findings in patients and non-human primate models. Br J Psychiatry Suppl 29:32-39.

Chen J, Zook D, Crickard L, and Tabatabaei A (2019) Effect of phosphodiesterase (1B, 2A, 9A and 10A) inhibitors on central nervous system cyclic nucleotide levels in rats and mice. Neurochem Int 129:104471.

Crow TJ (1980) Molecular pathology of schizophrenia: more than one disease process? BMJ 280:66-68.

Diamond A, Zola-Morgan S, and Squire LR (1989) Successful performance by monkeys with lesions of the hippocampal formation on $\mathrm{AB}$ and object retrieval, two tasks that mark developmental changes in human infants. Behav Neurosci 103: 526-537.

Dyck B, Branstetter B, Gharbaoui T, Hudson AR, Breitenbucher JG, Gomez L, Botrous I, Marrone T, Barido R, Allerston CK, et al. (2017) Discovery of selective phosphodiesterase 1 inhibitors with memory enhancing properties. $J$ Med Chem 60:3472-3483.

Enomoto T, Noda Y, and Nabeshima T (2007) Phencyclidine and genetic animal models of schizophrenia developed in relation to the glutamate hypothesis. Methods Find Exp Clin Pharmacol 29:291-301.

Girgis RR, Zoghbi AW, Javitt DC, and Lieberman JA (2019) The past and future of novel, non-dopamine-2 receptor therapeutics for schizophrenia: a critical and comprehensive review. J Psychiatr Res 108:57-83.

Glickman JF, Schmid A, and Ferrand S (2008) Scintillation proximity assays in highthroughput screening. Assay Drug Dev Technol 6:433-455.

Goldman-Rakic PS, Castner SA, Svensson TH, Siever LJ, and Williams GV (2004) Targeting the dopamine $\mathrm{D}_{1}$ receptor in schizophrenia: insights for cognitive dysfunction. Psychopharmacology (Berl) 174:3-16.

Goldsmith P, Affinito J, McCue M, Tsai M, Roepcke S, Xie J, Gertsik L, and Macek TA (2017) A randomized multiple dose pharmacokinetic study of a novel PDE10A inhibitor TAK-063 in subjects with stable schizophrenia and Japanese subjects and modeling of exposure relationships to adverse events. Drugs $R$ D 17:631-643. Grauer SM, Pulito VL, Navarra RL, Kelly MP, Kelley C, Graf R, Langen B, Logue S, Brennan J, Jiang L, et al. (2009) Phosphodiesterase 10A inhibitor activity in preclinical models of the positive, cognitive, and negative symptoms of schizophrenia. $J$ Pharmacol Exp Ther 331:574-590.

Horiguchi M, Hannaway KE, Adelekun AE, Huang M, Jayathilake K, and Meltzer HY (2013) $\mathrm{D}_{1}$ receptor agonists reverse the subchronic phencyclidine (PCP)-induced novel object recognition (NOR) deficit in female rats. Behav Brain Res 238:36-43.

Hufgard JR, Williams MT, Skelton MR, Grubisha O, Ferreira FM, Sanger H, Wright ME, Reed-Kessler TM, Rasmussen K, Duman RS, et al. (2017a) Phosphodiesterase$1 \mathrm{~b}$ (Pde1b) knockout mice are resistant to forced swim and tail suspension induced immobility and show upregulation of Pde10a. Psychopharmacology (Berl) 234: 1803-1813.

Hufgard JR, Williams MT, and Vorhees CV (2017b) Phosphodiesterase-1b deletion confers depression-like behavioral resistance separate from stress-related effects in mice. Genes Brain Behav 16:756-767.

Ishibashi T, Horisawa T, Tokuda K, Ishiyama T, Ogasa M, Tagashira R, Matsumoto K, Nishikawa H, Ueda Y, Toma S, et al. (2010) Pharmacological profile of lurasidone, a novel antipsychotic agent with potent 5 -hydroxytryptamine $7\left(5-\mathrm{HT}_{7}\right)$ and 5-HT $\mathrm{HA}_{1 \mathrm{~A}}$ receptor activity. $J$ Pharmacol Exp Ther 334:171-181.

Javitt DC and Zukin SR (1991) Recent advances in the phencyclidine model of schizophrenia. Am J Psychiatry 148:1301-1308.

Jentsch JD and Roth RH (1999) The neuropsychopharmacology of phencyclidine: from NMDA receptor hypofunction to the dopamine hypothesis of schizophrenia. Neuropsychopharmacology 20:201-225.

Jones DNC, Gartlon JE, Minassian A, Perry W, and Geyer MA (2008) Developing new drugs for schizophrenia: from animals to the clinic, in Animal and Translational 
Models for CNS Drug Discovery (McArthur RA and Borsini F eds) pp 199-261, Academic Press, Burlington, MA.

Kaiser T and Feng G (2015) Modeling psychiatric disorders for developing effective treatments. Nat Med 21:979-988.

Kelly MP, Adamowicz W, Bove S, Hartman AJ, Mariga A, Pathak G, Reinhart V, Romegialli A, and Kleiman RJ (2014) Select 3',5'-cyclic nucleotide phosphodiesterases exhibit altered expression in the aged rodent brain. Cell Signal 26: 383-397.

Khammy MM, Dalsgaard T, Larsen PH, Christoffersen CT, Clausen D, Rasmussen LK, Folkersen L, Grunnet M, Kehler J, Aalkjaer C, et al. (2017) PDE1A inhibition elicits cGMP-dependent relaxation of rat mesenteric arteries. $\mathrm{Br} J$ Pharmacol 174: $4186-4198$.

Kleiman RJ, Chapin DS, Christoffersen C, Freeman J, Fonseca KR, Geoghegan KF, Grimwood S, Guanowsky V, Hajós M, Harms JF, et al. (2012) Phosphodiesterase $9 \mathrm{~A}$ regulates central cGMP and modulates responses to cholinergic and monoaminergic perturbation in vivo. J Pharmacol Exp Ther 341:396-409.

Kotani M, Enomoto T, Murai T, Nakako T, Iwamura Y, Kiyoshi A, Matsumoto K, Matsumoto A, Ikejiri M, Nakayama T, et al. (2016) The atypical antipsychotic blonanserin reverses (+)-PD-128907- and ketamine-induced deficit in executive function in common marmosets. Behav Brain Res 305:212-217.

Krause M, Zhu Y, Huhn M, Schneider-Thoma J, Bighelli I, Nikolakopoulou A and Leucht S (2018) Antipsychotic drugs for patients with schizophrenia and predominant or prominent negative symptoms: a systematic review and metaanalysis. Eur Arch Psychiatry Clin Neurosci 268:625-639.

Lakics V, Karran EH, and Boess FG (2010) Quantitative comparison of phosphodiesterase mRNA distribution in human brain and peripheral tissues. Neuropharmacology 59:367-374.

Lewis DA and González-Burgos G (2008) Neuroplasticity of neocortical circuits in schizophrenia. Neuropsychopharmacology 33:141-165.

Li P, Zheng H, Zhao J, Zhang L, Yao W, Zhu H, Beard JD, Ida K, Lane W, Snell G, et al. (2016a) Discovery of potent and selective inhibitors of phosphodiesterase 1 for the treatment of cognitive impairment associated with neurodegenerative and neuropsychiatric diseases. J Med Chem 59:1149-1164.

Li YW, Seager MA, Wojcik T, Heman K, Molski TF, Fernandes A, Langdon S, Pendri A, Gerritz S, Tian Y, et al. (2016b) Biochemical and behavioral effects of PDE10A inhibitors: relationship to target site occupancy. Neuropharmacology 102:121-135.

Livak KJ and Schmittgen TD (2001) Analysis of relative gene expression data using real-time quantitative PCR and the $2^{-\Delta \Delta \mathrm{C}(\mathrm{T})}$ method. Methods 25:402-408.

Marvanová M, Ménager J, Bezard E, Bontrop RE, Pradier L, and Wong G (2003) Microarray analysis of nonhuman primates: validation of experimental models in neurological disorders. FASEB J 17:929-931.

McQuown S, Xia S, Baumgärtel K, Barido R, Anderson G, Dyck B, Scott R, and Peters M (2019) Phosphodiesterase 1b (PDE1B) regulates spatial and contextual memory in hippocampus. Front Mol Neurosci 12:21.

Murai T, Nakako T, Ikejiri M, Ishiyama T, Taiji M, and Ikeda K (2013) Effects of lurasidone on executive function in common marmosets. Behav Brain Res $\mathbf{2 4 6}$ $125-131$

Nabeshima T, Yamaguchi K, Yamada K, Hiramatsu M, Kuwabara Y, Furukawa H, and Kameyama T (1984) Sex-dependent differences in the pharmacological actions and pharmacokinetics of phencyclidine in rats. Eur J Pharmacol 97:217-227.

Nishi A and Snyder GL (2010) Advanced research on dopamine signaling to develop drugs for the treatment of mental disorders: biochemical and behavioral profiles of phosphodiesterase inhibition in dopaminergic neurotransmission. J Pharmacol Sci 114:6-16.

Omori K and Kotera J (2007) Overview of PDEs and their regulation. Circ Res 100 309-327.

Pekcec A, Schülert N, Stierstorfer B, Deiana S, Dorner-Ciossek C, and Rosenbrock H (2018) Targeting the dopamine $D_{1}$ receptor or its downstream signalling by inhibiting phosphodiesterase-1 improves cognitive performance. $\mathrm{Br} \mathrm{J}$ Pharmacol 175:3021-3033.

Polli JW and Kincaid RL (1994) Expression of a calmodulin-dependent phosphodiesterase isoform (PDE1B1) correlates with brain regions having extensive dopaminergic innervation. J Neurosci 14:1251-1261.

Qiao H, Noda Y, Kamei H, Nagai T, Furukawa H, Miura H, Kayukawa Y, Ohta T, and Nabeshima T (2001) Clozapine, but not haloperidol, reverses social behavior deficit in mice during withdrawal from chronic phencyclidine treatment. Neuroreport 12:11-15.
Reed TM, Repaske DR, Snyder GL, Greengard P, and Vorhees CV (2002) Phosphodiesterase 1B knock-out mice exhibit exaggerated locomotor hyperactivity and DARPP-32 phosphorylation in response to dopamine agonists and display impaired spatial learning. J Neurosci 22:5188-5197.

Remington G, Agid O, and Foussias G (2011) Schizophrenia as a disorder of too little dopamine: implications for symptoms and treatment. Expert Rev Neurother 11: 589-607.

Reneerkens OA, Rutten K, Steinbusch HW, Blokland A, and Prickaerts J (2009) Selective phosphodiesterase inhibitors: a promising target for cognition enhancement. Psychopharmacology (Berl) 202:419-443.

Sams-Dodd F (1999) Phencyclidine in the social interaction test: an animal model of schizophrenia with face and predictive validity. Rev Neurosci 10:59-90.

Schmidt CJ, Chapin DS, Cianfrogna J, Corman ML, Hajos M, Harms JF, Hoffman WE, Lebel LA, McCarthy SA, Nelson FR, et al. (2008) Preclinical characterization of selective phosphodiesterase 10A inhibitors: a new therapeutic approach to the treatment of schizophrenia. J Pharmacol Exp Ther 325:681-690.

Sharma T and Harvey P (2000) Cognition in Schizophrenia: Impairments, Importance, and Treatment Strategies, 1st ed, Oxford University Press, New York.

Shim S, Shuman M, and Duncan E (2016) An emerging role of cGMP in the treatment of schizophrenia: a review. Schizophr Res 170:226-231.

Siuciak JA, McCarthy SA, Chapin DS, Reed TM, Vorhees CV, and Repaske DR (2007) Behavioral and neurochemical characterization of mice deficient in the phosphodiesterase-1B (PDE1B) enzyme. Neuropharmacology 53:113-124.

Snyder GL, Prickaerts J, Wadenberg ML, Zhang L, Zheng H, Yao W, Akkerman S, Zhu H, Hendrick JP, Vanover KE, et al. (2016) Preclinical profile of ITI-214, an inhibitor of phosphodiesterase 1 , for enhancement of memory performance in rats. Psychopharmacology (Berl) 233:3113-3124.

Snyder GL and Vanover KE (2014) Intracellular signaling and approaches to the treatment of schizophrenia and associated cognitive impairment. Curr Pharm Des 20:5093-5103.

Strick CA, James LC, Fox CB, Seeger TF, Menniti FS, and Schmidt CJ (2010) Alterations in gene regulation following inhibition of the striatum-enriched phosphodiesterase, PDE10A. Neuropharmacology 58:444-451.

Sumiyoshi T, Enomoto T, Takai K, Takahashi Y, Konishi Y, Uruno Y, Tojo K, Suwa A, Matsuda H, Nakako T, et al. (2013) Discovery of novel $N$-substituted oxindoles as selective $\mathrm{M}_{1}$ and $\mathrm{M}_{4}$ muscarinic acetylcholine receptors partial agonists. ACS Med Chem Lett 4:244-248.

Sutcliffe JS, Marshall KM, and Neill JC (2007) Influence of gender on working and spatial memory in the novel object recognition task in the rat. Behav Brain Res 177:117-125.

Thompson WJ and Appleman MM (1971) Multiple cyclic nucleotide phosphodiesterase activities from rat brain. Biochemistry 10:311-316.

Uthayathas S, Masilamoni G.J, Shaffer CL, Schmidt C.J, Menniti FS, and Papa SM (2014) Phosphodiesterase 10A inhibitor MP-10 effects in primates: comparison with risperidone and mechanistic implications. Neuropharmacology 77:257-267.

Wallis JD, Dias R, Robbins TW, and Roberts AC (2001) Dissociable contributions of the orbitofrontal and lateral prefrontal cortex of the marmoset to performance on a detour reaching task. Eur J Neurosci 13:1797-1808.

Wennogle LP, Hoxie H, Peng Y, and Hendrick JP (2017) Phosphodiesterase 1: a unique drug target for degenerative diseases and cognitive dysfunction. Adv Neurobiol 17: 349-384.

Wilkinson LS, Dias R, Thomas KL, Augood S.J, Everitt BJ, Robbins TW, and Roberts AC (1997) Contrasting effects of excitotoxic lesions of the prefrontal cortex on the behavioural response to $\mathrm{D}$-amphetamine and presynaptic and postsynaptic measures of striatal dopamine function in monkeys. Neuroscience 80:717-730.

Woodward ND, Purdon SE, Meltzer HY, and Zald DH (2005) A meta-analysis of neuropsychological change to clozapine, olanzapine, quetiapine, and risperidone in schizophrenia. Int $J$ Neuropsychopharmacol 8:457-472.

Yan C, Bentley JK, Sonnenburg WK, and Beavo JA (1994) Differential expression of the $61 \mathrm{kDa}$ and $63 \mathrm{kDa}$ calmodulin-dependent phosphodiesterases in the mouse brain. J Neurosci 14:973-984.

Address correspondence to: Dr. Takeshi Enomoto, Drug Research Division, Sumitomo Dainippon Pharma, Co., Ltd., 33-94, Enoki-cho, Suita, Osaka 5640053, Japan. E-mail: takeshi-enomoto@ds-pharma.co.jp 